\title{
THE PROBLEM OF DRYING CLOTHES IN NEW HOME IN THE UK
}

\section{Introduction}

In the UK at present due to rising population and change in demographics, there is a significant push to deliver a new programme of housing that could see an additional three million homes or more than 10\% added to the Housing stock by 2020 (Pickles, 2014). According to the Department of Energy and Climate Change (2011), domestic homes use over $40 \%$ of UK energy and are responsible for 25\% of the country's $\mathrm{CO} 2$ emissions. The UK, like many other countries, is under an obligation to address these issues through comprehensive policy and market mechanisms particularly in the built environment sectors (McManus, 2010). In 2008 the government passed legislation to reduce greenhouse gas emissions by $80 \%$ by 2050 compared to levels in 1990 (Climate Change Act, 2008). This has led to the development of new standards for the building of these homes with changes implemented via a number of different pathways such as new building regulation including Standard Assessment Ratings (SAP) which is the methodology used to assess and compare the environmental performance of dwellings and new policy initiatives e.g. the Code for sustainable homes.

As the UK government continues to work with the house building industry to build these new dwellings to meet escalating demand, there have been a number of policy changes. Rather than homes being zero carbon there has been a primary focus on energy efficient fabric and services rather than integrated renewable generation in setting the standards. This has led to houses being built with high levels of insulation, minimum air loss and technologies incorporated within the structure to minimize energy and water use.

According to a report by Brook Lyndhurst (2012), English residents in seemingly identical homes with similar specifications for fabric and services use very different amounts of energy (gas). It was found that all householders made an effort to make their home 'comfortable', both in terms of aesthetics and in terms of temperature and concluded that the notion of the 'right' temperature appears to be highly individualised. A recent national study of the effects of feedback on domestic energy use (Wright and Nash, 2014) discovered that there were also considerable differences in energy use between similarly constructed homes. It was expected that energy use would be affected by occupancy levels, age, income level and the SAP score of the building but the study revealed there was no appreciable link between any of these. According to the report there has been much progress made in energy efficiency in the last few years by building homes that are more sustainable, however the way people 'behave' and 'use' energy needs to be fully researched if there is to be further progress made against targets.

This paper, which is part of a larger study of behaviour in new homes, explores how people behave with regards to laundry in new homes which are built highly insulated and air-tight; in particular it considers clothes drying; a seemingly ubiquitous task which will actually impact on every single new home which is currently under construction. The aim therefore of this paper is to understand the current practice of laundry drying in new homes in the UK in order to inform change to the way in which laundry is dried to review the impact on property and occupant well-being.

The paper is predominantly a review based paper but also includes the relevant findings of a wider study investigating the behaviour of occupants of new housing, in order to provide some initial observations and a basis upon which to expand the research.

\section{Recommendations currently available to designers for clothes drying}

There are a small number of advisory guides for designers and developers which set out desired provision for clothes drying in new homes in the UK: 
The code for sustainable homes $(\mathrm{CSH})$ provided one credit for the inclusion of a drying space. It stated that the clothes drying area must be secure and either designed for external or internal use. It also stipulated that internal rooms such as bedrooms, kitchens and living rooms are not allowed to incorporate drying spaces and drying spaces must comply with part $\mathrm{F}$ of the building regulations to prevent mould and condensation. The CSH went on to suggest that for one to two bedroom dwellings the drying equipment must be capable of holding at least four meters of drying line and for three bedroom dwellings the drying equipment must be capable of holding at least six metres of drying line.

In 2010 the code was amended to re-define the 'drying space' to require an intermittent extract rate of 30 litres per second $(30 \mathrm{l} / \mathrm{s})$. Alternatively an outbuilding or an external secured space is said to be acceptable ( $\mathrm{CSH}$ 2010). The CSH has never been mandatory for homes built to be privately owned, with private sector housing having only to meet the UK building regulations. However, for affordable housing, in addition to the building regulations, it has been compulsory to meet level three of the code (although the CSH was withdrawn in 2015 - there are still legacy cases where planning was granted with meeting the code as a requirement).

The Building Research Establishment Housing design handbook (BRE, 1995) produced as a reference to ensure housing criteria have been met describes an optimum laundry provision with regard to clothes drying and ironing. It points out that although airing and storage space was customarily provided, this requirement has now gone, for example in new houses airing cupboards is rarely constructed. It talks about 'good ventilation', heated cabinets, retractable lines, both inside and outside and suggests that lines of up to six metres per person are needed at spacing of more than $200 \mathrm{~mm}$ to provide sufficient air flow. It mentions concerns for people choosing to dry outside, highlighting issues with 'confidence in the British climate'.

Building regulations provide very little guidance specifically on clothes drying internally. Changes to Part L have been made with an aim to achieve cost effective abatement in the construction of new buildings and stimulate fabric focussed learning and innovation for more demanding future policies and savings on energy bills. Part F refers to ventilation within dwellings for health and well-being, odour control, airborne pollutants and excess humidity; neither part F or L specifically addresses the issue of drying clothes within dwellings.

According to the home laundry study (Menon and Porteus, 2011) it has become customary in Scotland for social housing providers to either supply a washer/dryer, or to designate a $600 \times 600 \mathrm{~mm}$ space with associated plumbing in the kitchen to allow the resident to install their own washer/dryer appliance. In the majority of new build social housing situations, there are no alternative drying spaces provided in the form of an airing cupboard, utility room or communal drying space (either externally or internally). Instead, as indicated in relation to the Scottish Technical Handbook, many of them rely on a retractable line over the bath as a suitable provision in order to satisfy the indoor passive drying regulation (Design guide for low energy laundering). The home laundry study specifically looked at social housing and considered homes of all ages.

There appears to be no accepted or recommendations currently to provide guidance to new volume house builders around the drying of laundry.

\section{Air tightness in New Homes and Mould}

Since 2006, Building regulations in England and Wales and Northern Ireland have required mandatory air leakage testing of new homes to prove that they meet the target air permeability. Developers have to prove that new houses are air tight; the benefit of air tightness in new dwellings is seen as considerable within the regulation frame-work since it increases the efficiency of the energy used to heat the building by stopping the warm air being lost and thereby contributes to the UK carbon reduction targets. 
It has been said that poor air tightness can be responsible for up to $40 \%$ of heat loss from buildings (NHBC, 2014). If air permeability is reduced from $10 \mathrm{cu} \mathrm{m}$ per hour to $7 \mathrm{cu} \mathrm{m}$ per hour this gives $90 \mathrm{~kg}$ of carbon saving per year per dwelling, which equates to 12,000 tons of saving per year in the UK domestic sector (DCLG, 2013).

The tightening of building envelopes, reduction of ventilation rates, use of new building technologies and techniques with unknown consequences and reliance on technologies to provide sufficient ventilation may significantly diminish the quality of indoor air (McGill et al 2015), since these standards are new there has been little time to assess the long term impact on building fabric and health of living in such air tight environments. Ventilation has become more important than ever in providing fresh air either within fixed ducted systems or with the introduction of trickle vents to windows.

Condensation can reasonably be described as the modern disease of buildings (Oliver, 1996). In the UK the levels of atmospheric water vapour are high compared with other parts of the world, this is due to the northern latitude and the fact that the prevailing westerly air flow picks up water vapour during its long passage over the Atlantic Ocean. Condensation is the formation of extra water vapour in the form of a liquid when saturation of the air occurs. The amount of water that can be present in the air is related to the ambient temperature; warmer air can contain more water vapour than cooler air. When the upper limit of water vapour is reached the air is said to be saturated. The actual water vapour in the air is expressed as relative humidity. House-hold activities contribute to the amount of water vapour in the air, actives such as breathing, cooking, bathing, washing and drying clothes all add moisture into the air and so must be removed.

According to the building regulations a ventilation rate of between 0.5 and 1.0 air changes per hour is considered sufficient to prevent moisture development in the air; and the relative humidity should not exceed $70 \%$ for a prolonged period to avoid the consequent risk of condensation and mould growth. This may be achieved by opening windows and in recent years trickle vents installed in double glazing units. Local extractor fans are used for intermittent purging of the 'wet' areas such as kitchens and bathrooms. It is however often the decision of the occupants to determine whether these trickle vents are opened or closed and the subsequent impact this has on ventilation of the dwelling can be great.

Due to the increased air tightness of new dwellings; ventilation is becoming increasingly important for the comfort and well-being of occupants. It can help to modify high temperatures during warm weather and is also needed to assist in the removal of polluted and vapour laden air. The main pollutant in dwellings is often found to be moisture which has been generated from cooking, washing and clothes drying. Good design in dwellings is normally based on inter-zonal ventilation in which either extract fans or passive ventilation stacks are located in the 'wet areas' of the dwelling. A recent study by McGill et al. (2015) has identified that relative humidity in houses studied which met code level 3 of the code for sustainable homes and were naturally ventilated rose above $70 \%$ which can give rise to mould. This is of concern since many of the houses currently being developed meet this standard and this is the required standard of UK building regulation.

There is a wide acceptance that mould growth in buildings should be avoided as it may lead to adverse health effects. In their guidelines to avoid mould growth in buildings Altamirano, Davies et al. (2009) refer to earlier work by Wooliscroft (1997) who stated that the high level of condensation and mould in the UK is the consequence of the small size of the dwellings, low temperatures, high humidity of the incoming air and high occupancy of the dwellings. The study found that $35 \%$ of dwellings were affected by condensation and $17 \%$ by mould growth. The size of houses in the UK has continued to reduce, in 2011 RIBA launched a major campaign to challenge the inadequate size of Britain's volume housing. Its report 'Case for Space' states that the average three bedroom home is around eight percent smaller than the minimum required in the London Plan, while the common 
design is smaller at $74 \mathrm{sq} \mathrm{m}$. This is $77 \%$ of the recommended size effectively missing two double bedrooms (RIBA 2011). The report exposed the lack of transparency around the size of UK homes.

Furthermore analysis of the 2001 Housing Condition database (ODPM, 2003) suggested that mould growth is related to the number of occupants within a dwelling. Altamirano et al (2009) suggest the following:

'Designers of new dwellings and those refurbishing existing properties require some mechanism for assessing the impact of design changes on mould growth. However the problem of mould growth in dwellings is not just technical but also related to occupant behaviour'.

Recent work by Sharpe et al (2015) suggests that a per unit increase in household energy efficiency (SAP rating) was associated with a tow to three percent increased risk of adults seeing a doctor for asthma in the last 12 months, with the strongest association in homes with SAP greater than or equal to 71, this was stated to be not statistically relevant but visible mould growth and presence of mould/ musty odour were found to be consistently associated with the current risk of asthma. This builds on work by Fisk et al. (2007) who undertook analysis of 33 studies investigating an association between occurrence of indoor dampness with adverse health effects. This found building dampness and mould to be associated with approximately $30-50 \%$ increase in respiratory and asthma related health outcomes.

Research into a number of parameters has led to improvement in the understanding of the problem of mould in new dwellings and its impact on the health of occupants, but there is little research around the behaviours with regard to the drying of laundry, particularly when it is being done inside of the dwelling.

\section{The science of clothes' drying}

Most new homes in the UK have a modern automatic washing machine, when washing is carried out much of the water is spun out at a high speed and drained away but even the most efficient machines leave water in clothes. David MacKay, in his book ' how people can use energy more efficiently' weighed laundry and discovered that a typical $4 \mathrm{~kg}$ load of dry washing emerged $2.2 \mathrm{~kg}$ heavier from the machine, this he deduced was equivalent to 2 litres of water. According to Oliver in his book Dampness in Buildings (1996) drying clothes can produce between 3-7.5 litres of moisture.

Clothes drying can be carried out in a number of ways but the most popular are as follows:

Drying Clothes Outdoors; The traditional method of drying clothes involves pegging them on a high line outside in a garden or communal space. This has the advantage removing the water outside of the property and using energy directly from the sun. In the UK however the weather is notoriously unpredictable and the variance in the daylight hours means people are home from work after dark for many months of the year. Additionally with the rise of the number of apartments being built with no external space, drying clothes outside is not an option.

Drying Clothes Indoors; In order to dry clothes indoors there is a requirement for energy to be added to evaporate the water. Drying clothes on radiators means the energy comes from the boiler and means more energy is required to heat the home. If the clothes are dried on a rack indoors the energy needed to evaporate the water comes from the ambient air in the room and the internal temperature will go down slightly to dry the damp clothes. In addition the water which evaporates will fill the home and may appear as condensation on the windows or walls which can lead to mould growth.

Tumble Drying; The simplest way to get rid of the water is to turn it into a vapour using a tumble dryer. Producing steam from the water in the clothes uses a large amount of energy; For example if the clothes contain $2 \mathrm{~kg}$ of water at $15{ }^{\circ} \mathrm{C}$, the water must be heated from 15 to $100{ }^{\circ} \mathrm{C}$ which uses approximately $700 \mathrm{~kJ}$ of energy, this then turns into $2 \mathrm{~kg}$ of steam at the same temperature using 
another 4,500 kJ of energy using 5,200 kJ or $1.4 \mathrm{kw}$ hours in total (Woodford, 2010). Tumble dryers are therefore expensive to run and use considerable energy at a time when government targets are aimed at delivering more sustainable homes, but drying clothes indoors also uses energy and creates moisture which may, in poorly ventilated homes, push relative humidity within internal spaces to a figure beyond $70 \%$, leading to condensation and mould growth.

Drying clothes externally is ideal but only when there is adequate space and dry weather.

\section{A revolution in laundry practice}

While the ever presence of laundry in the lives of many ordinary UK families seems blatantly obvious, it is often unconsidered. Pink et al (2015) found that laundry actually occupies a 'paradoxical status in the everyday, whereby it seemingly goes unnoticed, while it is actually a fundamental part of the materiality of a home and how the 'everyday' is organised'.

Ironically, laundry is a symbol of the 'ordinary', yet it is little discussed in the context of emergent understandings of what ordinary means or seemingly by designers of volume housing. In the book Housewife (Oakley, 1974), English women describe their daily routines, many of them being at home all day and make much reference to their laundry practice which was one of their time consuming tasks including; washing by hand, washing in a twin tub washing machine or washing in the bath, spin drying and hanging on a clothes horse in the bathroom or the outside line There is a reference to tumble dryers being available in launderettes but not within the home and not affordable for everyday use.

In 1996 Susan Henderson (Housing and Dwelling - Perspectives on Modern Domestic Architecture) wrote about the Franfurt Kitchen and the changes which took place between 1890 and 1918 with regards to women's work in the home. She refers to the 'electrified communal laundry' complete with washers, dryers mangles and irons and Lihotzky the leading female architect of the time calculated that this facility reduced a typical laundry day from fifteen to five hours.

Anecdotal evidence suggests that in the 1960s laundry took place in the UK on one day a week in a heated boiler followed by the use of a mangle used to wring clothes, and drying clothes outside on the line was very much the work of the 'house-wife' who spent much more time at home than women today. Since the late 1980s with the increasing affordability of the automatic washing machine followed by tumble dryers alongside a cultural revolution of women working outside of the home much has changed with regard to domestic chores.

According to more recent research carried out by the Energy Saving Trust, households will tend to own a washing machine, a washing machine and tumble dryer or washer-dryer. Lack of space is usually the reason for owning a washer-dryer as they are generally not considered to be as effective as separate laundry appliances. The average consumption of a washing machine was seen to be $166 \mathrm{kWh}$ with a total of 284 cycles a year, an average of 5.5 cycles per week. However this ranged from one to 22 cycles a week across the sample. The average annual consumption for clothes dryers was $394 \mathrm{kWh}$ with an average number of cycles of 260 per year. Importantly the report analysed that $80 \%$ of washes were followed by tumble drying, this is higher than estimated in the Market Transformation's Programmes current models and indicates that people are not fully utilising their outdoor space even in the summer.

In their ethnographical studies of research of 20 families' laundry and laundering activities in relation to everyday life, Pink et al (2015) suggest that laundry is not actually mundane and ordinary but leads to wider societal issues concerning health, climate change and domestic budgeting, this therefore demands more investigative research by built environment researchers - since the fabric of the buildings being constructed will be affected by the behaviours of those inside. Pink et al. state a wider proposal to extend the scope of the social sciences and humanities to make critical and 
influential interventions in fields beyond their own. They suggest how they might re-set the scene for understanding the contexts of the home for which energy consumption, demand and health issues related to indoor drying are lived. This is important in the context of the design of new housing where emergent trends in behaviour can seriously impact on how a home performs regardless of its fabric and services.

\section{Case Study}

As part of a wider study on behaviour within new homes by occupiers; questionnaires were delivered to all occupants of a recently completed housing estate examining their experience and behaviours within the new homes as passive adopters of the latest technologies. The questionnaires most specifically concentrated on those areas of the Code for Sustainable Homes with had been identified by the BRE as being influenced by resident's own behaviour including information on their laundry practice. Of the 65 occupied houses on the estate 20 questionnaires were returned; 19 from owner occupiers and one from affordable housing.

The case study presents a relatively small sample and indicates the situation on one new build estate only at this stage in the research. However the estate is seen as typical in design and construction of many new build housing estates within the UK (NHBC, 2015) and therefore aids in the generalisability of the results gained. It is also important to highlight that this was only one aspect of occupant behaviour being investigated but has emphasised the importance of the subject and indicated the need for further research.

With regard to laundry practice, occupiers were asked how they dry their clothes both in winter and summer, whether they were satisfied with these methods and if there were any disadvantages to these methods.

\subsection{Description of the case study}

The estate studied is an 'edge of town' new estate in Mid Sussex in the South of England. The development consists of 122 houses and flats on a residential site which includes the provision of 37 affordable dwellings and two large areas of open space totalling one hectare. The houses on the estate which are sold to private owners are mainly 3,4 and 5 bedroom detached dwellings which were built to meet policy and regulation and not built according to the Code for Sustainable homes. The affordable housing is built to a higher level of technology to meet level three of the CSH.

All units are heated with an individual gas boiler, with thermostatic controls to each radiator and additional thermostatic controls and pre-set timers for zonal applications. The building fabric construction is of traditional block with cavity insulation and external brick-work or cladding with lightweight internal partitions. All properties were constructed with high levels of thermal insulation; all properties comply with the latest building regulations. Smart meters were incorporated into the electrical supply but there was evidence that only few occupiers were aware of how to use these.

The majority of the houses whilst not being eco-homes represent the kind of homes being delivered on mass to meet new building regulation standards for private ownership and occupation in areas of the UK where local authorities are not requiring compliance with the Code for Sustainable homes through planning bodies. The affordable units are built with some government funding and thus meet level three of the CSH.

\subsection{Findings}

The initial findings of the study indicate that of all respondents, only the one from the affordable housing had been provided with a specific drying area, all of the privately owned dwellings $(95 \%$ of respondents) stated they had no specific space allocation for drying laundry within their property. 95\% of the respondents did however have access to an outside washing line which they used when 
weather and time allowed, however in winter and when weather did not allow, all but one respondent stated they used a tumble drier to dry their clothes in addition to the majority making use of a clothes airer within the property.

In terms of satisfaction, all respondents prefer to dry their clothes outside, however many stated that the weather prevents this much of the time. When discussing tumble drying, tumble dryers were used to save time in the drying of laundry and because occupants dislike the look of laundry hanging around their homes. It was also highlighted that there was a lack of air flow due to poor ventilation in the new homes meaning that clothes do not dry well on racks and so a tumble dryer is essential, however the cost of the energy to run a tumble dryer is of concern to the respondents.

\section{Discussion}

Analysis of the literature and case study shows that new homes being delivered on mass housing estates in the UK currently make no provision for the drying of laundry, with the exception of those built to be affordable who have received credits for implementing proper provision of clothes drying space. There is no single regulation which requires new build volume developers to provide obvious drying solutions to new residents and far too many new homes are built without systematic consideration of this daily task.

It would appear from the information available for the designer; the simplest cheapest healthiest option is to provide an external line for clothes drying, however from the resident's perspective this does little to address the real issue as on many days of the year outside clothes drying is actually impossible. Residents therefore appear to resort much of the time to drying clothes indoors on racks or airers (not in formal drying spaces or with adequate ventilation).

The Building regulations part $\mathrm{F}$ set out various strategies that should, if applied correctly ensure good ventilation regardless of the level of air tightness in new homes. Its focus is ventilation to provide fresh air for health and well-being, odour control, airborne pollutants and excess humidity, yet it does little to address the issues caused by passive clothes drying internally. There is emerging evidence of homes which are built to meet the current building regulations (Code 3) with natural ventilation which suffer with relative humidity greater than $70 \%$ which can lead to mould growth.

The increased use of tumble dryers in homes works against the government's philosophy to reduce energy use within domestic properties to work towards national targets and also the energy impact from drying clothes internally cannot be ignored. The Code for Sustainable Homes was developed to try to move towards more sustainable solutions for householders but with its recent demise and because it was never mandatory (only for affordable homes), it has had little success in changing the way the majority of new properties are designed.

With the decrease in permeability of new dwellings causing problems with air quality and mould, the demise of the house-wife, and the unpredictable climate; drying of laundry - a task carried out in almost every single home, must be addressed by designers and regulation.

\section{Conclusion}

The UK is in the process of revising standards of new build homes, this is to enable designers and contractors to build them more quickly and to make provision of an extra 3 million by 2020 to meet demographic need. It is important that in order that these homes do not add to greenhouse emissions; as the government target is to reduce the greenhouse emissions by $80 \%$, these new homes must perform in-use as well as to the technical standards to which they are built. This in-use performance though is based on an in depth understanding of the activities carried out within them and the behaviour of the residents. 
As building regulations pushes the air permeability of buildings below $10 \mathrm{~m}^{3} / \mathrm{m}^{2} \mathrm{hr} @ 50 \mathrm{~Pa}$, the provision of adequately controlled ventilation becomes increasingly important either through natural or mechanical means. Currently the focus of this ventilation is in spaces defined as 'wet' e.g. bathrooms and kitchens. Whilst these areas are recognized as key exporters of moisture in bathing and cooking activities there is little understanding of what people do with their wet laundry in new homes. Indeed there is evidence that people hang laundry in other areas of the home, which are not classified as 'wet' areas which can lead to moisture laden air, mould and poor health.

There is a developing body of research concerning air quality in increasingly air tight and energy efficient homes as concerns rise for the health, particularly with regard to respiratory health and the growth of mould contaminants. The problem with drying laundry internally is that it exasperates the issue of moisture laden air particularly in homes which are overcrowded and under ventilated and therefore performing efficiently in terms of energy use; and yet the alternatives which have been provided in volumetric new housing seem to be limited.

There is little evidence to suggest that designers of new homes make any consideration of how laundry will be undertaken, often providing space for a high energy tumble dryer in a kitchen or considering that washing will be dried outside. This situation is unlikely to improve under current regulations especially since the withdrawal of $\mathrm{CSH}$. Since there are too few new homes being built with any designated space for laundry activity, in particular passive indoor drying, this may be leading to a trend of moisture-laden living spaces which can create damp and mouldy environments.

As a result of this early exploratory research it is envisaged that further experimental and applied research needs to be undertaken to investigate the following:

- What regulations exist and how can they be best reviewed to incorporate changes in designs of new-build volume housing?

- How does drying laundry internally impact on air quality and relative humidity?

- How many days in a year can laundry be dried outside in the UK by use of longitudinal research.

- Can anything be learnt from other countries with similar climates about culture with regards to clothes drying?

- Can physical layouts for housing be changed to provide a shift in people's behaviours with regards to clothes drying?

In line with the review of other standards the intention is that this should assist in developing a strategic review of policy application and deliver projected reduction in energy use whilst maintaining the well-being of occupants living in new homes.

\section{REFERENCES}

Air Infiltration and Ventilation Centre (1996) A guide to Energy Efficient Ventilation AIVC: Coventry.

Altamirano-Medina et al (2009) Guidelines to avoid mould in buildings Advances in Building Energy Research (ABER) 3.1 (2009) 221-235.

Building Research Establishment (1995) BRE housing design handbook Energy and internal layout BRE Press: Watford.

Crump, Dengel et al (2009) Indoor Air Quality in Highly Efficient Homes NHBC Foundation published by BRE Press: Watford.

Department for Communities and Local Government (2012) Digest of United Kingdom Energy Statistics Department of Energy and Climate Change Crown Copy write. 
Department for Communities and Local Government (2011) The Carbon plan delivering our low carbon future DCLG: London.

Department for Communities and Local Government (2013) Proposed Changes to Part L of The Building Regulations Crown Copyright: London.

Fisk, W. J., Lei-Gomez, Q. and Mendell, M. J. (2007), Meta-analyses of the associations of respiratory health effects with dampness and mold in homes. Indoor Air, 17: 284-296.

Grainne McGill, Lukomon O.Odyedele, et al (2015) Case study investigation of indoor air quality in mechanically ventilated and naturally ventilated UK social Housing in' international journal of sustainable built environment $4^{\text {th }}$ March 2015

Lane B M (2007) Housing and Dwelling-Perspectives on Modern Domestic Architecture Routledge: Oxon.

McGill G, LO Oyedele, K McAllister (2015) Case study investigation of indoor air quality in mechanically and naturally ventilated uk social housing. International Journal of Sustainable Built Environment June 2015 Pages 58-77.

McManus A, MR Gaterell, LE Coates (2010) The potential of the Code for Sustainable Homes to deliver genuine 'sustainable energy' in the UK Social Housing Sector. Energy Policy.38(1) p2013-2019.

Menon R and Porteous C (2011) Healthy Low Energy Home Laundering Design Guide Mackintosh Environmental Architecture Research Unit: Glasgow.

NHBC (2014) Air-Leakage-Service retrieved from

http://www.nhbc.co.uk/Productsandservices/ConsultancyandTesting/Airleakageservics/FAQs / (Accessed 25.11.14).

NHBC (2015) Homes through the decades: The making of modern housing NHBC Foundation: London.

Oakley A (1974) Housewife Penguin Books Ltd: London.

Ofgem (2011) Typical domestic energy consumption figures retrieved from https://www.ofgem.gov.uk/ofgem-publications/64026/domestic-energy-consump-fig-fs.pdf (Accessed 13.01.15).

Oliver A (1996) Dampness in Buildings. $2^{\text {nd }}$ edition Blackwell Science Ltd: Chichester.

Pickles E (2014) Policy; Increasing the number of new houses Department of Communities and Local Government DCLG: London.

Pink S, (2016) MackleyK, Morosanu R Hanging out at home: Laundry as a thread and texture of everyday life International journal of cultural studies $2016 \mathrm{Vol} 18$.

RIBA(2011) campaigns over 'shameful shoeboxes' Building Design, RIBA: London.

Sharpe R, Thornton C et Al (2015) Higher energy efficient homes are associated with increased risk of doctor diagnosed asthma in a UK sub population. Environment International volume 75 Pages 234-244.

Woodford C (2010) Clothes Dryers retrieved from http//www.explain that stuff.com (Accessed 25.11.14).

Wright B, Nash B (2014) A study of the effects of feedback on domestic energy use National Energy Study Sustainable Homes: London. 